\title{
CURRENT STATUS OF THE PROJECT OF PHOTOGRAPHIC FOURFOLD COVERAGE OF THE NORTHERN HEMISPHERE OF SKY
}

\author{
V.S. KISLYUK \\ Main Astronomical Observatory \\ Ukrainian Academy of Sciences \\ $252127 \mathrm{Kiev}$ \\ USSR
}

The project of fourfold coverage of the northern hemisphere of the sky by means of wide-angle astrographs was proposed in 1977 (Kolchinsky and Onegina, 1977). This project is known as FON (fotograficheskij obzor neba) - photographic survey of sky.

The distinctive pecularity of the project FON is that it is carried out by means of not one but six of the same type astrographs (K.Zeiss, Jena) which have been installed at six observatories. All instruments have the same apertures $(D=400 \mathrm{~mm})$ but different focal lengths namely $F=2000 \mathrm{~mm}$ (Kiev, Zelenchuk, Zvenigorod, Dushanbe) and $\mathrm{F}=3000 \mathrm{~mm}$ (Abastumani and Kitab). Available fields of all instruments consist of $8^{\circ} \times 8^{\circ}$ and their working fields were adopted as $4^{\circ} \times 4^{\circ}$.

In order to ensure the fourfold coverage of sky six observatories were combined in the four groups as it is shown in Table 1. Each group photographs once the whole northern sky.

Between the groups the plate centres are displaced on $2^{\circ}$ in RA and/or DEC. Inside of each group the plate centres are displaced as shown in the table.

To consider the magnitude equation on each plate two exposures are made with duration of $18 \mathrm{~min}$ and $40 \mathrm{sec}$. It allows us to obtain the images of stars in the system B down to $15^{\mathrm{m}}-16^{\mathrm{m}}$ and $12^{\mathrm{m}}-13^{\mathrm{m}}$ correspondingly. A particular attention was paid to unique investigations of all astrographs (Ivanov et al, 1985).

Such analysis, including the characteristics of objectives, comparison of quantities of stellar images on plates, investigations of magnitude equation and other errors, allowed us to make conclusions about the excellent optics of all the instruments and to choose optimum conditions for observations.

Systematic observations on the FON project were started in 1982. At present nearly $90 \%$ of required plates have been obtained. The observations are suggested to be finished in 1991. The photographic collection will be used for determination of accurate positions and proper motions of all stars contained in the Astrographic Catalogue (Carte du Ciel) using the last one as the first epoch of observations.

Measurements of plates will be carried out by means of PARSEC (programme automatic radialscanner coordinatometer) which has been created recently (Sergeev et al, 1987). The Astrographic Catalogue will be used as the input catalogue for PARSEC. Preliminary analysis showed quite enough reliability and high accuracy of measurements of plates by means of this machine. 
Preliminary estimates of the accuracy of star positions from measurements of one plate give the values of errors of about $\pm(0$ ":30-0"35). It is expected that after the combining of all plates of fourfold coverage using overlapping plate techniques we will have an opportunity to obtain an accuracy of star positions $\pm(0$ "10 - 0"15). We also expect that using the data of Carte $\mathrm{du}$ Ciel the errors of proper motions of stars will be \pm 0.007 "/year.

Table 1. Number of plates of FON project

\begin{tabular}{|c|c|c|c|c|c|c|}
\hline Group & Station & From DEC & to DEC & RA & Num.of bands & Num.of plates \\
\hline \multirow[t]{5}{*}{1} & Kitab & $-4^{\circ}$ & $32^{\circ}$ & $16^{m}$ & 10 & 900 \\
\hline & Kiev & 32 & 60 & 16 & 8 & 720 \\
\hline & & 64 & 76 & 32 & 4 & 180 \\
\hline & & 80 & 84 & 64 & 2 & 44 \\
\hline & & 88 & 180 & 1 & 8 & \\
\hline \multirow[t]{4}{*}{2} & Zelenchuk & -6 & 58 & 16 & 17 & 1530 \\
\hline & & 62 & 74 & 32 & 4 & 180 \\
\hline & & 78 & 86 & 64 & 3 & 69 \\
\hline & & 90 & 360 & 1 & 4 & \\
\hline \multirow[t]{5}{*}{3} & Abastumani & ii -6 & 30 & 16 & 10 & 900 \\
\hline & Zvenigorod & d 30 & 58 & 16 & 8 & 720 \\
\hline & & 62 & 74 & 32 & 4 & 180 \\
\hline & & 78 & 86 & 64 & 3 & 69 \\
\hline & & 90 & 360 & 1 & 14 & \\
\hline \multirow[t]{4}{*}{4} & Dushanbe & -4 & 60 & 16 & 17 & 1530 \\
\hline & & 64 & 76 & 32 & 4 & 180 \\
\hline & & 80 & 84 & 64 & 2 & 44 \\
\hline & & 88 & 180 & 1 & 8 & \\
\hline
\end{tabular}

\section{References}

Kolchinsky, I.G., Onegina, A.B. (1977), Astrometrija i Astrofisika (Kiev), No 33, p.11-16.

Ivanov,G.A., Rachmatov,E., Yurevitch,V.A., et al (1988), Jenaer Rundschau, No 2, pp.90-91.

Sergeev,A.V., Sergeeva,T.P., Riabokon,A.V., et al (1987), Fundamentals of Astrometry, IAU Colloq. No 100, Beograd. 